\title{
Successful in vitro culture of pre-antral follicles derived from vitrified murine ovarian tissue: oocyte maturation, fertilization, and live births
}

\author{
Xiaoqian Wang, Sally Catt, Mulyoto Pangestu and Peter Temple-Smith \\ Monash Institute of Medical Research, Centre of Reproduction and Development, Monash University, Clayton, \\ Victoria 3168, Australia \\ Correspondence should be addressed to P Temple-Smith; Email: peter.temple-smith@monash.edu.au
}

X Wang is now at School of Paediatrics and Reproductive Health, Robinson Institute, Research Centre for Reproductive Health, University of Adelaide, Adelaide, South Australia 5005, Australia

\begin{abstract}
Cryopreservation of ovarian tissue is an important option for preserving the fertility of cancer patients undergoing chemotherapy and radiotherapy. In this study, we examined the viability and function of oocytes derived in vitro from pre-antral follicles as an alternative method for restoring fertility. Pre-antral follicles (specified as secondary follicle with a diameter around 100-130 $\mu \mathrm{m}$ ) were mechanically isolated from vitrified-warmed and fresh adult mouse ovarian tissues and cultured for 12 days followed by an ovulation induction protocol at the end of this period to initiate oocyte maturation. Oocytes were then released from these follicles, fertilized in vitro, and cultured to the blastocyst stage and vitrified. After storage in liquid nitrogen for 2 weeks, groups of vitrified blastocysts were warmed and transferred into pseudo-pregnant recipient females. Although most of the isolated mouse pre-antral follicles from fresh (79.4\%) and vitrified $(75.0 \%)$ ovarian tissues survived the 12-day in vitro culture period, significantly fewer mature oocytes developed from vitrifiedwarmed pre-antral follicles than from the fresh controls $(62.2 \mathrm{vs} 86.4 \%, P<0.05)$. No difference was observed in embryo cleavage rates between these two groups, but the proportion of embryos that developed into blastocysts in the vitrification group was only half that of the controls (24.2 vs $47.2 \%, P<0.05)$. Nevertheless, live births of healthy normal pups were achieved after transfer of vitrified blastocysts derived from both experimental groups. This study shows that successful production of healthy offspring using an in vitro follicle culture system is feasible, and suggests that this procedure could be used in cancer patients who wish to preserve their fertility using ovarian tissue cryopreservation.

Reproduction (2011) 141 183-191
\end{abstract}

\section{Introduction}

Ovarian stimulation, IVF, and embryo cryopreservation are well-established protocols commonly used in IVF centers and present an option for women with cancer to retain child-bearing potential prior to cancer treatment. They also provide an increasingly popular option for women who want, for various social reasons, to delay child-bearing but still retain their fertility (RodriguezWallberg \& Oktay 2010). However, for particular cohorts of women undergoing cancer treatments, some options are not appropriate; for example, embryo cryopreservation is not suitable for pre-pubertal girls, nor for most women without a male partner, unless the patient is willing to receive donor sperm (Lamar \& DeCherney 2009). Ovarian stimulation and oocyte cryopreservation avoids some of these disadvantages, but the application of this technique is currently limited by poor pregnancy rates of $1-5 \%$ (James \& Jacques 2004,
Oktay et al. 2006a). Mature oocytes are very sensitive to temperature changes and are less able to recover from cryoinjury than embryos. Abnormalities such as meiotic spindle depolarization, cytoskeletal disorganization, chromosome disruption, and/or zona hardening can be induced by cryoprotectant toxicity or ice crystal formation during cryopreservation procedures (Kim et al. 2001). Aside from difficulties arising from embryo or oocytes cryopreservation, many cancer patients are not able to delay their treatment to receive ovarian stimulation therapies to obtain a sufficient number of oocytes for freezing or IVF procedures. Moreover, in some invasive cancers, ovarian stimulation increases the risks of high levels of estrogen stimulating cancer growth, invasion, and recurrence (Oktay et al. 2006b).

Ovarian tissue cryopreservation has been proposed as an alternative strategy to preserve the fertility of cancer patients, especially pre-pubertal girls and women who cannot delay their cancer therapies (Donnez et al. 2006, 
Rodriguez-Wallberg \& Oktay 2010). The normal ovarian cortex contains a large population of primordial follicles, especially in younger women, which constitute over $90 \%$ of the total follicle population. These follicles are small in size, relatively quiescent metabolically, and their oocytes are smaller, lack a zona pellucida, meiotic spindle, and cortical granules. These characteristics make them far more tolerant to cryoinjury (Shaw et al. 2000). More importantly, contraindications for oocyte and embryo cryopreservation do not apply as ovarian stimulation is not required to harvest and freeze ovarian cortical tissue, and patients need not delay their cancer treatment (Gosden et al. 2002, Amorim et al. 2003, Donnez \& Dolmans 2009).

Two methods are used currently to cryopreserve ovarian tissue, slow cooling (Hovatta 2005, Isachenko etal.2007, Jin etal. 2010a) and vitrification (Li etal. 2007, Huang et al. 2008). Slow cooling remains the most widely used method clinically. Lower concentrations of cryoprotectant are required in freezing media for slow cooling, which reduces the risk of toxic and osmotic damage to cells, but this is insufficient to prevent ice crystal formation jeopardizing cell survival during the freezing procedures (Vajta 2006). Vitrification, though still regarded as a relatively novel freezing method, has recently been reported as an effective alternative method for the cryopreservation of ovarian tissue in various species, including mouse (Wang et al. 2009), rat (Deng et al. 2009), pig (Gandolfi et al. 2006), goat (Santos et al. 2007), sheep (Al-aghbari \& Menino 2002, Courbiere et al. 2006), monkey (Yeoman et al. 2005), and human (Keros et al. 2009, Zhou et al. 2010). It combines a high cooling rate with a high concentration of cryoprotectant in the vitrification media, which rapidly dehydrates the cells and prevents water from precipitating as ice (Vajta 2006).

Ovarian tissue grafting techniques have been used to restore ovarian function after cryopreservation, and live births have been reported after transplantation of cryopreserved ovarian tissues in animals (Gosden et al. 1994, Salle et al. 2003, Wang et al. 2009) and humans (Donnez et al. 2004, Meirow et al. 2005, Demeestere et al. 2007, Andersen et al. 2008, Silber et al. 2008, Sánchez-Serrano et al. 2010). However, extensive follicular damage and subsequent fibrosis are commonly observed after transplantation (Kim et al. 2002), and autotransplantation procedures have the added risk of transferring malignant cells back to the patient (Kim et al. 2001).

As an alternative, however, ovarian follicles can be isolated from fresh or cryopreserved ovarian tissues and cultured in vitro. This procedure decreases or totally eliminates the risk of transmitting malignant cells from cryopreserved ovarian tissue back into recipients and also allows direct monitoring and assessment of follicle quality during the maturation period (Amorim et al. 2009). Live pups have been obtained from culture of isolated pre-antral follicles from cryopreserved fetal, newborn, and immature mice (Cox et al. 1996, Liu et al. 2001, Migishima et al. 2003, Hasegawa et al. 2004); however, there has been no attempt to achieve pregnancies from in vitro culture of pre-antral follicles from adult animals.

In this study, a solid surface vitrification technique was used to cryopreserve adult mouse ovarian tissue. Fresh mouse ovarian tissue was used for experimental controls. The aims were 1 ) to evaluate the vitrification method for mouse ovarian tissue cryopreservation, by determining subsequent pre-antral follicle growth in vitro and oocyte survival and viability upon recovery from in vitro cultured follicles and 2) to assess the live birth rate after embryo transfer of vitrified-warmed blastocysts derived from in vitro fertilized oocytes collected from in vitro cultured, vitrified-warmed pre-antral follicles.

\section{Results}

\section{Histological assessment}

Morphological evaluation was performed to compare the structures of primordial, primary, and secondary follicles in fresh and vitrified-warmed adult mouse ovarian sections. Most pre-antral follicles displayed normal morphology after vitrification and warming and were similar to fresh controls (Fig. 1). The percentage of morphologically normal follicles at primordial, primary, and secondary stages was all significantly higher in the fresh control ovarian tissue when compared with the percentage from vitrified-warmed ovarian tissue $(P<0.05 ;$ Table 1$)$.

\section{In vitro pre-antral follicle growth}

A total of 209 and 244 pre-antral follicles were mechanically isolated from fresh $(n=18)$ and vitrifiedwarmed $(n=22)$ adult mouse ovaries respectively. All the pre-antral follicles were cultured individually in vitro for 12 days, and the morphology and growth stages were recorded every other day (Fig. 2). Most of the isolated pre-antral follicles $(75.0 \%)$ from the vitrification group survived the in vitro culture period, as did fresh isolated follicles (79.4\%; Table 2). Follicle degeneration, identified by extrusion of denuded oocytes and darkening of the ooplasm, usually occurred in the first 6 days.

\section{Oocyte maturation and IVF of mouse pre-antral follicles derived from fresh and vitrified-warmed ovarian tissues}

In both treatment groups after follicle culture, around $80 \%$ of follicles formed antral-like cavities, of which $50 \%$ spontaneously released the oocytes after ovulation induction (Fig. 3). Follicles that did not ovulate spontaneously but showed clear cavity formation were gently teased to release oocytes. From the 

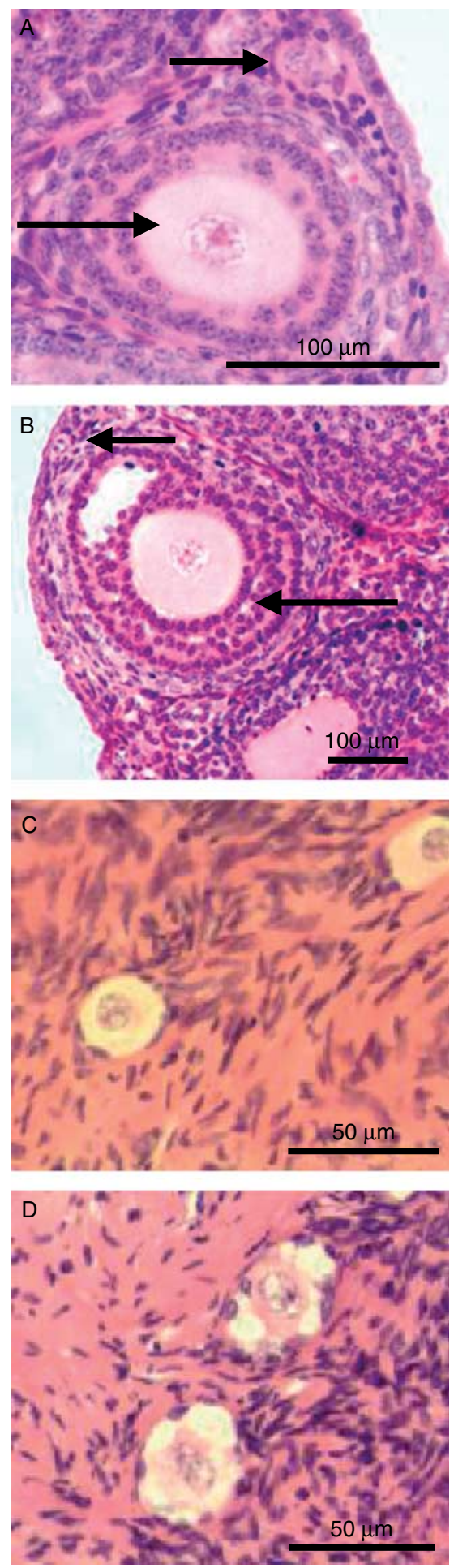

Figure 1 Morphology of adult mouse ovarian tissues before and after vitrification. (A) Fresh tissue displaying a morphologically normal primordial follicle (small arrow) and a secondary follicle (large arrow) composed of intact oocytes and well-organized granulosa cells. (B) In vitrified-warmed ovarian tissue, the primordial follicle (small arrow) and antral follicle (large arrow) were all morphologically normal. (C) In vitrified-warmed tissue, a normal primordial follicle with an intact oocyte surrounded by a well-organized flattened layer of granulosa cells. (D) Two abnormal primordial follicles with shrunken oocytes. vitrified-warmed ovarian tissues, a total of 172 oocytes were recovered and $107(62.2 \%)$ matured to metaphase II (MII) stage. This was significantly lower than the control group, for which the MII formation rate was $86.4 \%(140 / 162, P<0.05)$. The vitrification group yielded a significantly higher proportion of oocytes $(50 / 172,29.1 \%)$ in germinal vesicle breakdown (GVBD)/metaphase I (MI) stage than that from controls $(14 / 162,8.6 \%, P<0.05)$, but $G V$ rates were not different between the groups (vitrification: 15/172, 8.7\%; control: 8/162, 4.9\%, $P>0.05$; Table 2).

\section{In vitro development of inseminated MII oocytes}

A total of 140 and $107 \mathrm{MII}$ oocytes from the control and vitrification groups respectively underwent IVF. In the vitrification group, $61.7 \%$ (66/107) cleaved into two-cell embryos, which was not significantly different from controls (89/140, 63.6\%). However, blastocyst formation rate in the vitrification group was significantly lower than that in the control group $(16 / 66,24.2 \%$ vs $42 / 89,47.2 \%$, $P<0.05$; Fig. 3 and Table 3).

\section{Blastocyst recovery and viability after cryopreservation and embryo transfer}

All blastocysts (graded 1 or 2) that developed from the control and vitrification groups after 4 or 5 days in vitro embryo culture were vitrified and stored in liquid nitrogen $\left(\mathrm{LN}_{2}\right)$. After 1 month, 16 blastocysts from the vitrified-warmed ovarian tissue group and 32 from the fresh ovarian tissue group were warmed. After warming and $2 \mathrm{~h}$ of post-thaw culture in blastocyst medium, 13 $(81.3 \%)$ blastocysts from the vitrified-warmed tissue group and $28(87.5 \%)$ from the fresh tissue group showed signs of re-expansion, and all were transferred into three surrogate recipients (one recipient for the vitrified tissue group and two for the fresh tissue group). All three recipients became pregnant and delivered. In the vitrification group, two healthy pups (one male and one female; live birth rate $12.5 \%$ ) were born from the transfer of 16 blastocysts derived from in vitro cultured pre-antral follicles, and ten healthy pups (six male and four female; live birth rate $31.3 \%$ ) were born from the transfer of 32 blastocysts from in vitro cultured pre-antral follicles in unfrozen control group. No unhealthy or stillborn pups were produced from either group.

Table 1 Comparison of the percentage of morphologically normal mouse follicles between fresh and vitrified ovarian tissue groups.

\begin{tabular}{llll}
\hline $\begin{array}{l}\text { Treatment } \\
\text { group* }\end{array}$ & $\begin{array}{l}\text { Primordial } \\
\text { follicles }\end{array}$ & $\begin{array}{l}\text { Primary } \\
\text { follicles }\end{array}$ & $\begin{array}{l}\text { Secondary } \\
\text { follicles }\end{array}$ \\
\hline Fresh & $89.80 \pm 2.33 \%^{\mathrm{a}}$ & $88.80 \pm 1.65 \%^{\mathrm{a}}$ & $89.17 \pm 2.28 \% \mathrm{a}$ \\
Vitrification & $82.57 \pm 0.60 \%^{\mathrm{b}}$ & $82.03 \pm 1.48 \%^{\mathrm{b}}$ & $79.93 \pm 1.88 \%{ }^{\mathrm{b}}$ \\
\hline
\end{tabular}

*Different superscripts within the same column indicate significant difference $(P<0.05)$. 

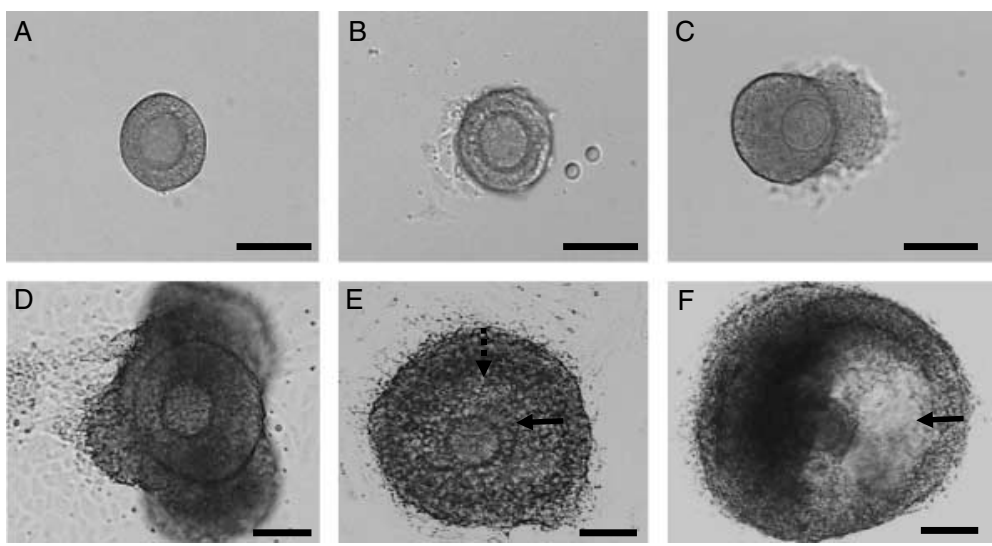

Figure 2 Follicle growth in vitro from day 0 to 10 . (A) On day 0 , morphologically normal pre-antral follicles were isolated and cultured in vitro. (B) On day 2 of culture, follicles remained intact, and cells from the surface of the follicle started to adhere to the dish. (C) By day 4, some theca and granulosa cells had proliferated and penetrated the basal membrane. (D) By day 6, the basement membrane had been completely breached, and the majority of follicles were reorganizing their structure in culture. (E) On day 8, follicles had reorganized, and multiple layers of granulosa cells (bold arrow) were clearly distinguished from theca cell layers (dashed arrow). (F) Antrum-like cavity formation was observed as early as day 8 and is demonstrated by an arrow in the day- 10 follicle shown. Scale bar: $100 \mu \mathrm{m}$.
All pups developed normally to weaning age. A total of four pups (two siblings from the ovarian tissue vitrification group and two siblings from the fresh ovarian tissue control group) were mated, and all produced normal-sized healthy offspring (vitrification: seven pups, three male, and four female; fresh: eight pups, five male, and three female).

\section{Discussion}

Vitrification is a simple, convenient, and efficient method for embryo and oocyte cryopreservation in both animal and human models (Fujihira et al. 2004, Campos-Chillòn et al. 2009, Cao et al. 2009, Keros et al. 2009, Selman et al. 2009, Zhou et al. 2010). However, data on ovarian tissue vitrification are still limited, and the results are often conflicting and controversial (Choi et al. 2008, Isachenko et al. 2009, Kagawa et al. 2009). We have previously shown that a solid surface vitrification protocol was successful in cryopreserving adult mouse ovarian tissue, and subsequent renal grafting of thawed vitrified tissue showed that this combination was successful for the preservation and restoration of fertility in mouse (Wang et al. 2009). This study used a pre-antral follicle culture system to examine the viability of vitrified-warmed adult mouse ovarian tissue without the need for grafting or other surgical intervention to restore ovarian function and fertility. Live births achieved from vitrified blastocysts derived from oocytes isolated from in vitro cultured pre-antral follicles from fresh and vitrified-warmed adult mouse ovarian tissue have not been reported previously.
Histological examination confirmed that adult mouse ovarian tissue could be successfully cryopreserved using the solid surface vitrification method (Wang et al. 2009). Though the percentage of morphologically normal follicles at different developmental stages in vitrified-warmed tissue was significantly lower than that in fresh ovarian tissue, a large proportion of pre-antral follicles $(\sim 80 \%)$ in the vitrified ovarian tissue retained normal morphology, and there was no difference in the follicle survival rate between fresh and vitrified-warmed follicles after 12 days in culture. A similar result was reported with human primordial follicles after solid surface vitrification and warming by Huang et al. (2008). This group also demonstrated that there was no significant difference in the rate of apoptosis in either primordial follicles or stromal cells examined by TUNEL assay between vitrified and fresh ovarian tissue.

While morphological analysis is useful, in vitro or in vivo culture of tissue and the production of live offspring are required to confirm the viability and normal function of vitrified-thawed ovarian tissues. Live offspring have been reported after transplantation of vitrifiedwarmed ovarian tissue into newborn or adult mice (Hani et al. 2006, Kagawa et al. 2007). Until now, however, the production of live offspring from primordial and pre-antral follicles from cryopreserved/thawed ovarian tissue and cultured to mature in vitro has only been reported in immature mice (Liu et al. 2001, O'Brien et al. 2003, Hasegawa et al. 2006). No live births have previously been reported using adult mouse ovaries, and although development of follicles to the antral stage has been observed in human ovarian tissue cultured

Table 2 Oocyte maturation in mouse pre-antral follicles from fresh and vitrified-warmed ovarian tissues after 12 days culture in vitro.

\begin{tabular}{|c|c|c|c|c|c|c|}
\hline \multirow[b]{2}{*}{ Groups* } & \multirow{2}{*}{$\begin{array}{c}\text { Number of follicles } \\
\text { cultured (number of replicates) }\end{array}$} & \multirow{2}{*}{$\begin{array}{l}\text { Number }(\%) \text { of follicles } \\
\text { survived after } 12 \text { days }\end{array}$} & \multirow{2}{*}{$\begin{array}{l}\text { Number }(\%) \text { of } \\
\text { oocytes recovered }\end{array}$} & \multicolumn{3}{|c|}{ Number $(\%)$ of oocyte with } \\
\hline & & & & GV & GVBD/MI & MII \\
\hline Fresh & $209(5)$ & $166(79.4 \%)$ & 162 & $8(4.9 \%)$ & $14(8.6 \%)^{\mathrm{a}}$ & $140(86.4 \%)^{\mathrm{a}}$ \\
\hline Vitrification & $244(6)$ & $183(75.0 \%)$ & 172 & 15 (8.7\%) & $50(29.1 \%)^{b}$ & $107(62.2 \%)^{b}$ \\
\hline
\end{tabular}

GV, germinal vesicle; GVBD, germinal vesicle breakdown; MI, metaphase I; MII, metaphase II. *Different superscripts within the same column indicate significant difference $(P<0.05)$. 

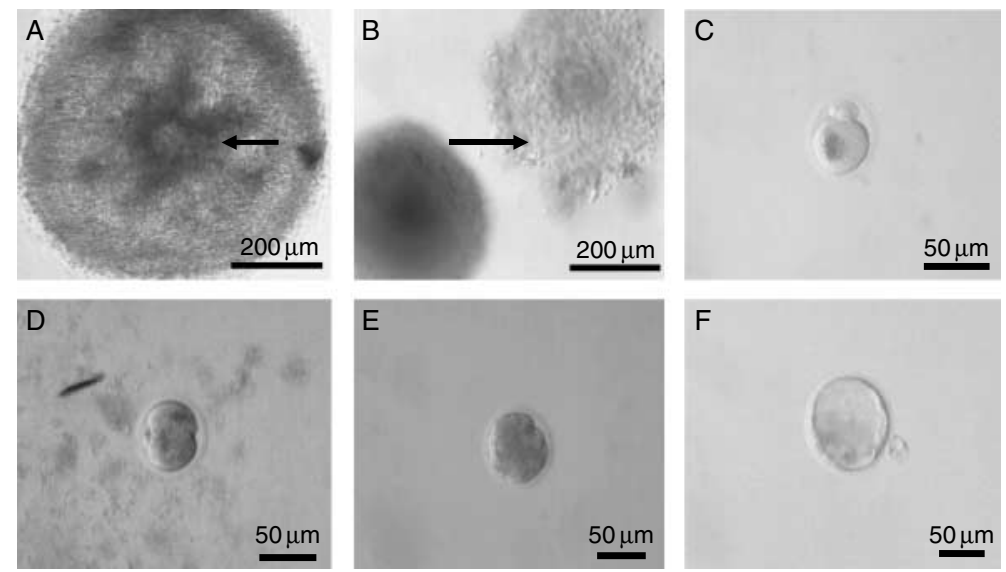

Figure 3 In vitro ovulation, fertilization, and embryo development of an oocyte released from a 12-day-old cultured pre-antral follicle. (A) A pre-ovulatory follicle formed after 12 days of culture in vitro, showing an oocyte surrounded by a layer of cumulus cells (arrowhead) and antrum (arrow). (B) Day 13, after 14 h hCG stimulation, a mucified cumulus-oocyte complex (arrowhead) has ruptured from the follicle (arrow). (C) Mature MII oocyte with one polar body. (D) Two-cell embryo. (E) Morula.

(F) Hatching blastocyst. in vitro (Isachenko et al. 2003, Xu et al. 2009), there have been no reports assessing the competency of the oocytes obtained from these in vitro grown follicles.

The results presented here demonstrate that pre-antral follicles isolated from fresh or vitrified-warmed adult mouse ovarian tissue survive and develop to the antral stage after 12 days culture in vitro. The follicle survival, oocyte maturation and fertilization rates, and subsequent developmental potential were similar to those reported previously using an immature mouse model (Liu et al. 2001, O'Brien et al. 2003, Hasegawa et al. 2006). Moreover, the efficiency of in vitro follicle culture was similar to the tissue transplantation system reported by our group previously (Wang et al. 2009), with 244 cultured pre-antral follicles resulting in 16 blastocysts, from which two pups were obtained (2/16 transferred, $12.5 \%)$. The transplantation study, using the same in vitro maturation (IVM), IVF, and embryo culture system, yielded 107 blastocysts from 26 vitrified quarterovary grafts (and several times more follicles than the number cultured in the follicle culture study) resulting in the same live birth rate of around $12.5 \%$. However, the 244 follicles isolated for culture were obtained from almost twice as many ovaries (44 vs 26 in the transplantation study), indicating that a high proportion of follicles are lost during the follicle isolation procedure. Herein lies the main source of inefficiency in the follicle isolation and culture system, which needs to be further improved for this to become a viable and an effective method for clinical treatments. Oocyte maturation is the key process in the follicle culture system and is often examined only by nuclear maturity, which is characterized by the extrusion of one polar body. However, cytoplasmic maturation is also critical for oocyte developmental competence and for these oocytes to successfully fertilize and develop normally throughout the pre-implantation period (Picton 2002). Using a mouse model, it has been shown that the capacity for oocyte maturation and IVF is reduced for oocytes retrieved from small antral follicles compared with those from large antral follicles, and that oocytes need to reach their full size to undergo nuclear and cytoplasmic maturation (Eppig \& Schroeder 1989). Future investigations into the molecular mechanisms of folliculogenesis and oogenesis in various species and how to simulate these in vitro will help to optimize the efficiency of follicle culture.

In conclusion, this is the first report of live births after vitrification and warming of adult mouse ovarian tissue, followed by isolation and culture of pre-antral follicles, oocyte maturation and fertilization in vitro, and embryo transfer with vitrified-warmed blastocysts. It is significant that the implantation rate and live birth rate of blastocysts derived from this in vitro-based protocol, which included in vitro culture to the blastocyst stage, are not different from the partial in vivo system involving ovarian tissue grafting prior to the IVM stage reported previously (Wang et al. 2009). The use of cryopreservation at both or either ends of this in vitro protocol allows the potential for great flexibility in women when offering a fertility preservation plan, with the ability to suspend the process at the most suitable time point in the protocol for each individual. This protocol also presents a potential option to avoid surgical intervention for women wishing to restore their ovarian function using their cryopreserved ovarian tissue. However, based on the nature of the human ovarian tissue (more than 90\% of the follicles are at primordial but not at pre-antral stage) and the prolonged follicle developmental period (Gougeon 1996), further experiments to improve the

Table 3 Developmental capacity of mouse oocytes derived from in vitro cultured pre-antral follicles after IVF.

\begin{tabular}{|c|c|c|c|}
\hline \multirow[b]{2}{*}{ Groups* } & \multirow{2}{*}{$\begin{array}{l}\text { Number of } \\
\text { MII oocytes }\end{array}$} & \multicolumn{2}{|c|}{$\begin{array}{l}\text { Number (\%) of oocytes } \\
\text { developed into }\end{array}$} \\
\hline & & Two-cell & Blastocyst \\
\hline Fresh & 140 & $89(63.6 \%)$ & $42(47.2 \%)^{\mathrm{a}}$ \\
\hline Vitrification & 107 & $66(61.7 \%)$ & $16(24.2 \%)^{b}$ \\
\hline
\end{tabular}

${ }^{*}$ Different superscripts within the same column indicate significant difference $(P<0.05)$. 
efficiency of in vitro follicle culture and oocyte maturation are still needed, especially the establishment of a successful primordial follicle isolation and in vitro culture system to achieve higher success rates for future clinical application. The two-stage in vitro culture strategies recently described in the mouse (Jin et al. $2010 b$ ) using a three-dimensional hydrogel matrix for secondary follicles, which produced a high rate of MII oocytes with over $50 \%$ of fertilized oocytes progressing to two-cell embryos, and in the human (Telfer et al. 2008), in which exposure to activin resulted in $30 \%$ of primordial/primary follicles showing normal morphology, intact oocytes, and antral formation at the end of a 10-day culture period, are promising directions for future experimental and clinical approaches.

\section{Materials and Methods}

All the chemicals and reagents used for this study were purchased from Sigma Chemical Company (Sigma), unless otherwise stated.

\begin{abstract}
Animals
Ethical approval for this study was obtained from the Monash Medical Centre Animal Ethics Committee (AEC Approval No. MMCA2008/15). F1 C57BL ×CBA hybrid female mice $(n=40), 6-7$ weeks old, were used as ovarian tissue donors. F1 C57BL $\times$ CBA hybrid females $(n=3)$, 8 weeks old, were mated with proven vasectomized $\mathrm{F} 1 \mathrm{C} 57 \mathrm{BL} \times \mathrm{CBA}$ hybrid males and used as pseudo-pregnant embryo transfer recipients. F1 C57BL $\times$ CBA hybrid males, 12 weeks old, were used as sperm donors for IVF. All mice were obtained from Monash University Animal Services and housed in a conventional animal house under a $12 \mathrm{~h}$ light: $12 \mathrm{~h}$ darkness cycle with a relative humidity of $30-60 \%$ and a temperature ranging from 21 to $24{ }^{\circ} \mathrm{C}$. All mice had free access to fresh food and water.
\end{abstract}

\section{Ovarian tissue collection}

Female donor mice were killed by cervical dislocation, and their ovaries were removed and placed into HEPES-buffered KSOM handling medium (KSOM HM; Summers et al. 1995) supplemented with $0.5 \% \mathrm{w} / \mathrm{v}$ BSA. Each ovary was then cut into roughly equal quarters using a razor blade (ProSciTech, Brisbane, Queensland, Australia) before vitrification. Experimental controls consisted of pre-antral follicle isolated from fresh ovaries and used immediately for in vitro follicle culture.

\section{Ovarian tissue vitrification}

Ovarian tissue samples were vitrified and warmed as described previously (Wang et al. 2009). In brief, quartered ovaries were initially exposed to $10 \%(\mathrm{v} / \mathrm{v}) / 1.8 \mathrm{M}$ ethylene glycol (EG) and $10 \%(\mathrm{v} / \mathrm{v}) / 1.4 \mathrm{M}$ DMSO in KSOM HM for $20 \mathrm{~min}$ at room temperature to achieve osmotic equilibration. This was followed by a second equilibration in $17 \%(\mathrm{v} / \mathrm{v}) / 3 \mathrm{M} \mathrm{EG}$, $17 \%(\mathrm{v} / \mathrm{v}) / 2.3 \mathrm{M} \mathrm{DMSO}$, and $0.75 \mathrm{M}$ sucrose for $3 \mathrm{~min}$ at room temperature. Each ovarian fragment was then loaded with a minimum volume $(1-3 \mu \mathrm{l})$ of the vitrification solution onto the hook of a plastic Fibreplug and was vitrified immediately by contacting the hooked end of the Fibreplug with the surface of a metal block (CVM kit, Cryologic, Melbourne, Victoria, Australia), which was immersed in $\mathrm{LN}_{2}$. Each Fibreplug was then inserted into its corresponding storage sleeve and plunged into pre-cooled goblets for storage in $\mathrm{LN}_{2}$. To warm the ovarian tissue fragments, Fibreplugs were removed from the storage straw and immersed in $0.5 \mathrm{M}$ sucrose in KSOM HM for 5 min at $37^{\circ} \mathrm{C}$, and then the tissue fragments were washed through stepwise sucrose solutions $(0.25,0.125$, and $0.0 \mathrm{M}$ sucrose in $\mathrm{KSOM} \mathrm{HM}, 5 \mathrm{~min}$ each). After washing and prior to follicle isolation, the tissues were held in $\mathrm{KSOM} \mathrm{HM}$ at $37^{\circ} \mathrm{C}$.

\section{Histological examination}

Fresh and vitrified-warmed ovaries ( $n=4$ per treatment group) were fixed for $24 \mathrm{~h}$ in Bouin's fixative, dehydrated manually through a graded ethanol series, embedded in paraffin, and serial sectioned at $5 \mu \mathrm{m}$ thickness. Sections were stained with hematoxylin and eosin and examined using an Olympus CX41 upright microscope (Olympus, Tokyo, Japan). Follicles were counted in every fifth serial section of each sample, and only follicles containing oocytes with a visible nucleus were included to avoid double counting. Follicles were classified as follows: 1) primordial follicle: one layer of flattened granulosa cells surrounding the oocyte; 2) primary follicles: one layer of cuboidal granulosa cells surrounding the oocyte; and 3) secondary follicles: two or more layers of cuboidal granulosa cells without antrum formation (Jones \& Krohn 1961). Antral follicles were not counted in this study. Normal follicle morphology was defined as a follicle containing an intact, round oocyte surrounded by well-organized granulosa cells and theca cell layers. Abnormal follicles contained oocytes that often appeared shrunken after vitrification, with pyknotic nuclei, reduced ooplasm, and/or a disorganized arrangement of granulosa cells (Fig. 1).

\section{Isolation of pre-antral follicles}

Pre-antral follicles $(100-130 \mu \mathrm{m})$ were mechanically isolated from either fresh or vitrified ovarian tissues. Briefly, follicles were isolated in KSOM HM under a dissecting microscope at $37^{\circ} \mathrm{C}$ by gently teasing them out with two 26 gauge needles attached to $1 \mathrm{ml}$ syringes. Only those follicles with the following characteristics were selected for culture: 1) morphologically normal pre-antral follicles with one or two layers of granulosa cells and some attached theca cells; 2) a visible round oocyte located centrally within the pre-antral follicles. All selected follicles from different treatment groups were cultured in different dishes (60 mm Petri dishes, Falcon, Becton Dickinson, Franklin Lakes, NJ, USA) under the same culture conditions.

\section{In vitro culture of pre-antral follicles}

Washed pre-antral follicles were cultured in a medium described by Cortvrindt et al. (1996) with some modifications. The culture medium consisted of $\alpha$-minimum essential medium 
(Invitrogen) supplemented with 5\% heat-inactivated FCS (Invitrogen), $5 \mu \mathrm{g} / \mathrm{ml}$ insulin, $5 \mu \mathrm{g} / \mathrm{ml}$ transferrin, $5 \mathrm{ng} / \mathrm{ml}$ selenium (ITS), $50 \mathrm{mIU} / \mathrm{ml}$ penicillin, $50 \mu \mathrm{g} / \mathrm{ml}$ streptomycin, and $2 \mu \mathrm{g} / \mathrm{ml} \mathrm{FSH}$ (Folltropin-V, BIONICHE Animal Health Canada Inc. Belleville, Ontario, Canada). Culture dishes were pre-equilibrated and contained fifteen $10 \mu \mathrm{l}$ culture droplets and three $30 \mu \mathrm{l}$ washing droplets, covered with $5 \mathrm{ml}$ mineral oil. Pre-antral follicles were washed through the washing droplets and placed individually into the culture droplets. On day 2 of culture, each droplet was supplemented with $10 \mu \mathrm{l}$ fresh and equilibrated culture medium. Following this, the diameter of the follicle at the basal membrane and granulosa and theca cell differentiation in the pre-antral follicles were recorded, and half of the medium $(10 \mu \mathrm{l})$ was replaced every other day. All follicles were cultured in $5 \% \mathrm{CO}_{2}$ in air for 12 days at $37^{\circ} \mathrm{C}$.

\section{In vitro maturation of oocytes from pre-antral follicles}

On day 12 of culture, ovulation was induced by adding $5 \mathrm{ng} / \mathrm{ml}$ recombinant human epidermal growth factor (Invitrogen) and $1.5 \mathrm{IU} / \mathrm{ml}$ human chorionic gonadotropin (Chorulon, Intervet Canada Corp., Kirkland, Quebec, Canada) into pre-antral follicle culture droplets (Cortvrindt et al. 1996, Liu et al. 2001). After 14-16 h, oocyte release was observed (and aided, if required), and the presence and mucification of the cumulus were recorded using an inverted microscope.

\section{IVF and oocyte maturation assessment}

All cumulus-oocyte complexes (COCs) were inseminated in vitro as described previously by Wang et al. (2009). Sperm samples for IVF were obtained from the caudae epididymides of 12-week-old male F1 C57BL $\times$ CBA mice. The caudae were divided in half and placed in $1 \mathrm{ml}$ preequilibrated modified Tyrode's solution (MT6; Fraser 1984) in a $5 \mathrm{ml}$ Falcon tube (BD Biosciences, San Jose, CA, USA) to release sperm samples into the medium. After 30 min incubation at $37{ }^{\circ} \mathrm{C}$ in $5 \% \mathrm{CO}_{2}$ in air, the supernatant containing a high number of motile sperm was harvested, and the sperm concentration and motility were assessed before insemination. Insemination dishes were prepared the day before with $100 \mu$ l MT6 media droplets covered with a layer of mineral oil in $60 \mathrm{~mm}$ Falcon dishes and allowed to equilibrate at $37{ }^{\circ} \mathrm{C}$ in $5 \%$ $\mathrm{CO}_{2}$ in air for at least $12 \mathrm{~h}$. COCs from different treatment groups were inseminated in different dishes with $1 \times 10^{6}$ spermatozoa $/ \mathrm{ml}$ for $2-4 \mathrm{~h}$. At the end of this period, after the cumulus had been dispersed, the immature oocytes were scored (scoring as follows: immature: GV visible, GV absent but no polar body recognizable (GVBD; MI); mature: evidence of at least one polar body, MII), counted, and removed.

\section{In vitro culture of embryo}

All inseminated oocytes assessed as mature were washed and cultured in Sydney IVF Cleavage Medium (COOK Australia, Brisbane, Queensland, Australia) for 2 days and transferred to Sydney IVF Blastocyst Medium (COOK Australia) from day 3 until day 5 at $37^{\circ} \mathrm{C}$ in $6 \%$
$\mathrm{CO}_{2}, 5 \% \mathrm{O}_{2}$ atmosphere. Embryo cleavage and blastocyst assessments were performed at $24 \mathrm{~h}$ and $4-5$ days post insemination respectively.

\section{Blastocyst vitrification and warming}

All day- 4 or day- 5 blastocysts were graded before vitrification using the following criteria: Grade 1 blastocyst - tightly packed inner cell mass and trophectoderm with many cells; Grade 2 blastocyst - loosely packed inner cell mass and trophectoderm with few cells; Grade 3 blastocyst - significant vacuoles, fragments, and/or signs of degeneration. Only Grade 1 or 2 blastocysts were vitrified, and all the other embryos were discarded.

For vitrification, blastocysts were initially equilibrated in KSOM HM containing 10\% v/v EG and 10\% v/v DMSO for $3 \mathrm{~min}$ at $37^{\circ} \mathrm{C}$, then transferred to vitrification solution in KSOM HM containing $17 \% \mathrm{v} / \mathrm{v}$ EG, $17 \% \mathrm{v} / \mathrm{v} \mathrm{DMSO}$, and $0.75 \mathrm{M}$ sucrose for $30 \mathrm{~s}$ at $37^{\circ} \mathrm{C}$. Each blastocyst was then aspirated in $2 \mu \mathrm{l}$ of vitrification solution and placed onto the hooked end of a plastic Fibreplug. This was touched to the surface of a pre-cooled metal alloy block immersed in $\mathrm{LN}_{2}$. Fibreplugs were subsequently placed individually into their corresponding plastic sleeves and plunged into $\mathrm{LN}_{2}$ in pre-cooled goblets for storage.

To warm blastocysts, Fibreplugs were removed from the straw and submerged immediately into $0.3 \mathrm{M}$ sucrose solution in $\mathrm{KSOM} \mathrm{HM}$ at $37^{\circ} \mathrm{C}$. Blastocysts were immediately retrieved and transferred through a series of three solutions $(0.25,0.15$, and $0.0 \mathrm{M}$ sucrose in $\mathrm{KSOM} \mathrm{HM})$ for $5 \mathrm{~min}$ each at $37^{\circ} \mathrm{C}$. All warmed blastocysts were cultured in Sydney IVF Blastocyst Medium at $37^{\circ} \mathrm{C}$ in $6 \% \mathrm{CO}_{2}, 5 \%$ $\mathrm{O}_{2}$ atmosphere for $2 \mathrm{~h}$ before being scored and transferred to recipients.

\section{Embryo transfer}

F1 C57BL $\times$ CBA female mice ( $n=3 ; 8$ weeks old) were used as embryo transfer recipients after mating with vasectomized F1 males from the same strain. The females were checked for the evidence of vaginal plugs after mating. Recovered blastocysts from each treatment group were transferred into the uterus of a separate day-2.5 pseudo-pregnant recipient using the method described by Nagy et al. (2003) and used previously by Wang et al. (2009). Briefly, recipients were anaesthetized (Avertin $(20 \mathrm{mg} / \mathrm{ml} \mathrm{2,} \mathrm{2,} \mathrm{2-tribromoethanol} \mathrm{and}$ $2 \% \mathrm{v} / \mathrm{v}$ tert-amyl alcohol), $0.4 \mathrm{mg} / \mathrm{g}$ body weight, i.p.). A $1 \mathrm{~cm}$ skin incision was made in the dorsal midline at the level of the last rib, and the skin was separated from the underlying tissues using blunt dissection until the ovarian fat pad was visible under the abdominal wall on each side. A $0.5 \mathrm{~cm}$ incision was made in the abdominal wall over the ovarian fat pad, which was gently pulled out to expose the oviduct, ovary, and the upper part of uterus. Up to eight embryos in $3-5 \mu \mathrm{l}$ of KSOM HM were transferred into each uterine horn by using a fine glass pipette. Each uterine horn was then returned to the body cavity, and the skin incision was closed with Michel clips (Clay Adams, Sparks, MD, USA). All recipients were allowed to deliver and raise pups. 
Pups were either raised to weaning age to check their post-natal development or mated with their siblings from the same litter for fertility testing.

\section{Statistical analysis}

The percentage of morphologically normal follicles at different stages in different treatment groups was analyzed by one-way ANOVA, and data are presented as mean \pm s.E.M. Oocyte maturation, cleavage, blastocyst, and live birth rates in each of the different treatment groups were analyzed using the $\chi^{2}$ test, and the results were considered to be significantly different when $P<0.05$. SPSS 12.0.1. (SPSS Inc., Chicago, IL, USA) was used for all statistical analyses.

\section{Declaration of interest}

The authors declare that there is no conflict of interest that could be perceived as prejudicing the impartiality of the research reported.

\section{Funding}

This research did not receive any specific grant from any funding agency in the public, commercial or not-for-profit sector.

\section{References}

Al-aghbari AM \& Menino AR 2002 Survival of oocytes recovered from vitrified sheep ovarian tissues. Animal Reproduction Science $\mathbf{7 1}$ 101-110. (doi:10.1016/S0378-4320(02)00011-8)

Amorim CA, Goncalves PB \& Figueiredo JR 2003 Cryopreservation of oocytes from pre-antral follicles. Human Reproduction Update $\mathbf{9}$ 119-129. (doi:10.1093/humupd/dmg014)

Amorim CA, Van Langendonckt A, David A, Dolmans M-M \& Donnez J 2009 Survival of human pre-antral follicles after cryopreservation of ovarian tissue, follicular isolation and in vitro culture in a calcium alginate matrix. Human Reproduction 24 92-99. (doi:10.1093/humrep/ den343)

Andersen CY, Rosendahl M, Byskov AG, Loft A, Ottosen C, Dueholm M, Schmidt KL, Andersen AN \& Ernst E 2008 Two successful pregnancies following autotransplantation of frozen/thawed ovarian tissue. Human Reproduction 23 2266-2272. (doi:10.1093/humrep/den244)

Campos-Chillòn LF, Suh TK, Barcelo-Fimbres M, Seidel GE Jr \& Carnevale EM 2009 Vitrification of early-stage bovine and equine embryos. Theriogenology 71 349-354. (doi:10.1016/j.theriogenology. 2008.08.001)

Cao Y-X, Xing Q, Li L, Cong L, Zhang Z-G, Wei Z-L \& Zhou P 2009 Comparison of survival and embryonic development in human oocytes cryopreserved by slow-freezing and vitrification. Fertility and Sterility 92 1306-1311. (doi:10.1016/j.fertnstert.2008.08.069)

Choi J, Lee B, Lee E, Yoon B-K, Bae D \& Choi D 2008 Cryopreservation of ovarian tissues temporarily suppresses the proliferation of granulosa cells in mouse preantral follicles. Cryobiology 56 36-42. (doi:10.1016/j. cryobiol.2007.10.174)

Cortvrindt R, Smitz J \& Van Steirteghem AC 1996 In vitro maturation, fertilization and embryo development of immature oocytes from early preantral follicles from prepuberal mice in a simplified culture system. Human Reproduction 11 2656-2666.

Courbiere B, Odagescu V, Baudot A, Massardier J, Mazoyer C, Salle B \& Lornage J 2006 Cryopreservation of the ovary by vitrification as an alternative to slow-cooling protocols. Fertility and Sterility $\mathbf{8 6}$ 1243-1251. (doi:10.1016/j.fertnstert.2006.05.019)
Cox S-L, Shaw J \& Jenkin G 1996 Transplantation of cryopreserved fetal ovarian tissue to adult recipients in mice. Journal of Reproduction and Fertility 107 315-322. (doi:10.1530/jrf.0.1070315)

Demeestere I, Simon P, Emiliani S, Delbaere A \& Englert Y 2007 Fertility preservation: successful transplantation of cryopreserved ovarian tissue in a young patient previously treated for Hodgkin's disease. Oncologist 12 1437-1442. (doi:10.1634/theoncologist.12-121437)

Deng X, Zheng H, Yu X, Yu H, Zhang C, Chao L, Li R \& Liu W 2009 Cryopreserved ovarian tissues can maintain a long-term function after heterotopic autotransplantation in rat. Reproduction 138 519-525. (doi:10.1530/REP-09-0151)

Donnez J \& Dolmans MM 2009 Cryopreservation of ovarian tissue: an overview. Minerva Medica 100 401-413.

Donnez J, Dolmans MM, Demylle D, Jadoul P, Pirard C, Squifflet J, Martinez-Madrid B \& Van Langendonckt A 2004 Livebirth after orthotopic transplantation of cryopreserved ovarian tissue. Lancet 364 1405-1410. (doi:10.1016/S0140-6736(04)17222-X)

Donnez J, Martinez-Madrid B, Jadoul P, Van Langendonckt A, Demylle D \& Dolmans MM 2006 Ovarian tissue cryopreservation and transplantation: a review. Human Reproduction Update 12 519-535. (doi:10.1093/ humupd/dml032)

Eppig J \& Schroeder A 1989 Capacity of mouse oocytes from preantral follicles to undergo embryogenesis and development to live young after growth, maturation, and fertilization in vitro. Biology of Reproduction 41 268-276. (doi:10.1095/biolreprod41.2.268)

Fraser LR 1984 Mouse sperm capacitation in vitro involves loss of a surfaceassociated inhibitory component. Journal of Reproduction and Fertility 72 373-384. (doi:10.1530/jrf.0.0720373)

Fujihira T, Kishida R \& Fukui Y 2004 Developmental capacity of vitrified immature porcine oocytes following ICSI: effects of cytochalasin B and cryoprotectants. Cryobiology 49 286-290. (doi:10.1016/j.cryobiol. 2004.08.004)

Gandolfi F, Paffoni A, Papasso Brambilla E, Bonetti S, Brevini TAL \& Ragni G 2006 Efficiency of equilibrium cooling and vitrification procedures for the cryopreservation of ovarian tissue: comparative analysis between human and animal models. Fertility and Sterility 85 1150-1156. (doi:10.1016/j.fertnstert.2005.08.062)

Gosden RG, Baird DT, Wade JC \& Webb R 1994 Restoration of fertility to oophorectomized sheep by ovarian autografts stored at -196 degrees. Human Reproduction 9 597-603.

Gosden RG, Mullan J, Picton HM, Yin H \& Tan SL 2002 Current perspective on primordial follicle cryopreservation and culture for reproductive medicine. Human Reproduction Update 8 105-110. (doi:10.1093/ humupd/8.2.105)

Gougeon A 1996 Regulation of ovarian follicular development in primates: facts and hypotheses. Endocrine Reviews 17 121-155. (doi:10.1210/ edrv-17-2-121)

Hani T, Tachibe T, Shingai S, Kamada N, Ueda O \& Jishage K-I 2006 Fertility of mice receiving vitrified adult mouse ovaries. Reproduction 131 681-687. (doi:10.1530/rep.1.01030)

Hasegawa A, Hamada Y, Mehandjiev T \& Koyama K 2004 In vitro growth and maturation as well as fertilization of mouse preantral oocytes from vitrified ovaries. Fertility and Sterility 81 824-830. (doi:10.1016/j. fertnstert.2003.08.028)

Hasegawa A, Mochida N, Ogasawara T \& Koyama K 2006 Pup birth from mouse oocytes in preantral follicles derived from vitrified and warmed ovaries followed by in vitro growth, in vitro maturation, and in vitro fertilization. Fertility and Sterility 86 1182-1192. (doi:10.1016/j. fertnstert.2005.12.082)

Hovatta O 2005 Methods for cryopreservation of human ovarian tissue. Reproductive Biomedicine Online 10 729-734. (doi:10.1016/S14726483(10)61116-9)

Huang L, Mo Y, Wang W, Li Y, Zhang Q \& Yang D 2008 Cryopreservation of human ovarian tissue by solid-surface vitrification. European Journal of Obstetrics, Gynecology, and Reproductive Biology 139 193-198. (doi:10.1016/j.ejogrb.2008.03.002)

Isachenko E, Isachenko V, Rahimi G \& Nawroth F 2003 Cryopreservation of human ovarian tissue by direct plunging into liquid nitrogen. European Journal of Obstetrics, Gynecology, and Reproductive Biology 108 186-193. (doi:10.1016/S0301-2115(02)00465-7) 
Isachenko V, Isachenko E, Reinsberg J, Montag M, van der Ven K, Dorn C, Roesing B \& van der Ven H 2007 Cryopreservation of human ovarian tissue: comparison of rapid and conventional freezing. Cryobiology $\mathbf{5 5}$ 261-268. (doi:10.1016/j.cryobiol.2007.08.008)

Isachenko V, Lapidus I, Isachenko E, Krivokharchenko A, Kreienberg $\mathbf{R}$, Woriedh M, Bader M \& Weiss JM 2009 Human ovarian tissue vitrification versus conventional freezing: morphological, endocrinological, and molecular biological evaluation. Reproduction 138 319-327. (doi:10.1530/REP-09-0039)

James JS \& Jacques C 2004 An overview of oocyte cryopreservation. Reproductive Biomedicine Online 9 152-163. (doi:10.1016/S14726483(10)62124-4)

Jin S, Lei L, Shea LD, Zelinski MB, Stouffer RL \& Woodruff TK 2010a Markers of growth and development in primate primordial follicles are preserved after slow cryopreservation. Fertility and Sterility 93 2627-2632. (doi:10.1016/j.fertnstert.2009.11.029)

Jin SY, Lei L, Shikanov A, Shea LD \& Woodruff TK $2010 \mathrm{~b}$ A novel twostep strategy for in vitro culture of early-stage ovarian follicles in the mouse. Fertility and Sterility 93 2633-2639. (doi:10.1016/j.fertnstert. 2009.10.027)

Jones EC \& Krohn PL 1961 The relationships between age, numbers of oocytes and fertility in virgin and multiparous mice. Journal of Endocrinology 21 469-495. (doi:10.1677/joe.0.0210469)

Kagawa N, Kuwayama M, Nakata K, Vajta G, Silber S, Manabe N \& Kato O 2007 Production of the first offspring from oocytes derived from fresh and cryopreserved pre-antral follicles of adult mice. Reproductive Biomedicine Online 14 693-699. (doi:10.1016/S14726483(10)60670-0)

Kagawa N, Silber S \& Kuwayama M 2009 Successful vitrification of bovine and human ovarian tissue. Reproductive Biomedicine Online 18 568-577. (doi:10.1016/S1472-6483(10)60136-8)

Keros V, Xella S, Hultenby K, Pettersson K, Sheikhi M, Volpe A, Hreinsson J \& Hovatta O 2009 Vitrification versus controlled-rate freezing in cryopreservation of human ovarian tissue. Human Reproduction 24 1670-1683. (doi:10.1093/humrep/dep079)

Kim SS, Battaglia DE \& Soules MR 2001 The future of human ovarian cryopreservation and transplantation: fertility and beyond. Fertility and Sterility 75 1049-1056. (doi:10.1016/S0015-0282(01)01790-3)

Kim SS, Soules MR \& Battaglia DE 2002 Follicular development, ovulation, and corpus luteum formation in cryopreserved human ovarian tissue after xenotransplantation. Fertility and Sterility 78 77-82. (doi:10.1016/ S0015-0282(02)03144-8)

Lamar CA \& DeCherney AH 2009 Fertility preservation: state of the science and future research directions. Fertility and Sterility 91 316-319. (doi:10. 1016/j.fertnstert.2008.08.133)

Li YB, Zhou CQ, Yang GF, Wang Q \& Dong Y 2007 Modified vitrification method for cryopreservation of human ovarian tissues. Chinese Medical Journal 120 110-114.

Liu J, Van der Elst J, Van den Broecke R \& Dhont M 2001 Live offspring by in vitro fertilization of oocytes from cryopreserved primordial mouse follicles after sequential in vivo transplantation and in vitro maturation. Biology of Reproduction 64 171-178. (doi:10.1095/biolreprod64.1.171)

Meirow D, Levron J, Eldar-Geva T, Hardan I, Fridman E, Zalel Y, Schiff E \& Dor J 2005 Pregnancy after transplantation of cryopreserved ovarian tissue in a patient with ovarian failure after chemotherapy. New England Journal of Medicine 353 318-321. (doi:10.1056/NEJMc055237)

Migishima F, Suzuki-Migishima R, Song S, Kuramochi T, Azuma S, Nishijima M \& Yokoyama M 2003 Successful cryopreservation of mouse ovaries by vitrification. Biology of Reproduction 68 881-887. (doi:10.1095/biolreprod.102.007948)

Nagy A, Gersenstein M, Vintersten K \& Behringer R 2003 Surgical Procedures. In Manipulating the Mouse Embryo: A Laboratory Manual, 3rd edn, pp 251-289. New York: Cold Spring Harbour Laboratory Press.

O'Brien MJ, Pendola JK \& Eppig JJ 2003 A revised protocol for in vitro development of mouse oocytes from primordial follicles dramatically improves their developmental competence. Biology of Reproduction 68 1682-1686. (doi:10.1095/biolreprod.102.013029)

Oktay K, Cil AP \& Bang H 2006a Efficiency of oocyte cryopreservation: a meta-analysis. Fertility and Sterility 86 70-80. (doi:10.1016/j.fertnstert. 2006.03.017)

Oktay K, Hourvitz A, Sahin G, Oktem O, Safro B, Cil A \& Bang H 2006 b Letrozole reduces estrogen and gonadotropin exposure in women with breast cancer undergoing ovarian stimulation before chemotherapy. Journal of Clinical Endocrinology and Metabolism 91 3885-3890. (doi:10.1210/jc.2006-0962)

Picton HM 2002 Oocyte maturation in vitro. Current Opinion in Obstetrics and Gynecology 14 295-302. (doi:10.1097/00001703-2002 06000-00009)

Rodriguez-Wallberg KA \& Oktay K 2010 Fertility perservation medicine: options for young adults and children with cancer. Journal of Pediatric Hematology/Oncology 32 390-396. (doi:10.1097/MPH.0b013e3181 dce339)

Salle B, Demirci B, Franck M, Berthollet C \& Lornage J 2003 Long-term follow-up of cryopreserved hemi-ovary autografts in ewes: pregnancies, births, and histologic assessment. Fertility and Sterility 80 172-177. (doi:10.1016/S0015-0282(03)00554-5)

Sánchez-Serrano M, Crespo J, Mirabet V, Cobo AC, Escribá MJ, Simón C \& Pellicer A 2010 Twins born after transplantation of ovarian cortical tissue and oocyte vitrification. Fertility and Sterility 93 268e11-268e13. (doi:10.1016/j.fertnstert.2009.09.046)

Santos RR, Tharasanit T, Van Haeften T, Figueiredo JR, Silva JR \& Van den Hurk R 2007 Vitrification of goat preantral follicles enclosed in ovarian tissue by using conventional and solid-surface vitrification methods. Cell and Tissue Research 327 167-176. (doi:10.1007/s00441006-0240-2)

Selman H, Brusco GF, Fiorini F, Barnocchi N, Mariani M \& El-Danasouri I 2009 Vitrification is a highly efficient method to cryopreserve human embryos in in vitro fertilization patients at high risk of developing ovarian hyperstimulation syndrome. Fertility and Sterility 91 1611-1613. (doi:10. 1016/j.fertnstert.2008.12.027)

Shaw JM, Oranratnachai A \& Trounson AO 2000 Fundamental cryobiology of mammalian oocytes and ovarian tissue. Theriogenology 53 59-72. (doi:10.1016/S0093-691X(99)00240-X)

Silber SJ, DeRosa M, Pineda J, Lenahan K, Grenia D, Gorman K \& Gosden RG 2008 A series of monozygotic twins discordant for ovarian failure: ovary transplantation (cortical versus microvascular) and cryopreservation. Human Reproduction 23 1531-1537. (doi:10.1093/ humrep/den032)

Summers MC, Bhatnagar PR, Lawitts JA \& Biggers JD 1995 Fertilization in vitro of mouse ova from inbred and outbred strains: complete preimplantation embryo development in glucose-supplemented KSOM. Biology of Reproduction 53 431-437. (doi:10.1095/biolreprod53.2.431)

Telfer EE, McLaughlin M, Ding C \& Thong KJ 2008 A two-step serum-free culture system supports development of human oocytes from primordial follicles in the presence of activin. Human Reproduction 23 1151-1158. (doi:10.1093/humrep/den070)

Vajta G 2006 Are programmable freezers still needed in the embryo laboratory? Review on vitrification Reproductive Biomedicine Online 12 779-796. (doi:10.1016/S1472-6483(10)61091-7)

Wang X, Catt S, Pangestu M \& Temple-Smith P 2009 Live offspring from vitrified blastocysts derived from fresh and cryopreserved ovarian tissue grafts of adult mice. Reproduction 138 527-535. (doi:10.1530/ REP-09-0148)

Xu M, Barrett SL, West-Farrell E, Kondapalli LA, Kiesewetter SE, Shea LD \& Woodruff TK 2009 In vitro grown human ovarian follicles from cancer patients support oocyte growth. Human Reproduction 24 2531-2540. (doi:10.1093/humrep/dep228)

Yeoman RR, Wolf DP \& Lee DM 2005 Coculture of monkey ovarian tissue increases survival after vitrification and slow-rate freezing. Fertility and Sterility 83 1248-1254. (doi:10.1016/j.fertnstert.2004.11. 036)

Zhou XH, Wu YJ, Shi J, Xia YX \& Zheng SS 2010 Cryopreservation of human ovarian tissue: comparison of novel direct cover vitrification and conventional vitrification. Cryobiology 60 101-105. (doi:10.1016/j. cryobiol.2009.02.006)

Received 8 September 2010

First decision 6 October 2010

Accepted 12 November 2010 